\title{
DEVELOPMENT AND DSP IMPLEMENTATION OF ANN-BASED VPWM IN A VOLTAGE SOURCE INVERTER
}

This paper deals with development, simulation and DSP implementation of space vector modulator based on artificial neural network. The modulator is designed for a voltage source inverter utilization. In the contribution an explanation of presented ANN-based VSI-VPWM is described. Main features and advantages of the used algorithm are summarized too. The entire AC electrical drive consists of a frequency converter, induction motor and microprocessor control system. In the paper a description of the control system with TMS 320C40 DSP is also given. A very important part of the development is simulation, because it is necessary to verify rightness of the algorithm. The entire drive was simulated in the program Matlab with Simulink toolbox.

Keywords: DSP, Artificial Neural Network (ANN), Vector Pulse-Width Modulation (VPWM), Voltage Source Inverter (VSI), Induction motor, Simulation

\section{Introduction}

Induction motors are often a preferred choice in variable-speed drive applications. The PWM inverters are most commonly applied in such induction motor drives. The PWM voltage source inverter, based on IGBTs, has gained a dominant position in AC drives market due to its ease of application, good power factor and potential to provide good dynamic performance.

Pulse-width modulation (PWM) has been one of the most intensively studied areas of power electronics in the past three decades. The fast development of the switching capabilities of power semiconductor switches requires faster, more accurate and simpler modulation techniques. Although the digital implementation of a spacevector modulator is simple, the required computations for the pulse times and the corresponding execution times limit the minimum sampling time. However, to reduce hardware and software complexity, to increase the accuracy, and to reduce the required computation times, it is also possible to use an ANN-based space-vector modulator, which utilizes vector classification concepts associated with competitive ANNs [1].

The on-line implementation of the conventional space-vector modulator requires that at every sampling time the sector where the space-vector reference lie must be established, and pulse times must be evaluated too. It follows that the trigonometric function sin must also be computed on-line. In one possible form of the conventional implementation, the sine function is stored in a look-up table.

However, this approach has two main disadvantages:

- Use of any look-up table requires additional memory.

- Interpolation of non-linear functions leads to poor accuracy and thus to increased harmonics in the PWM waveforms.
It is possible to use such technique where the direct computation of trigonometric functions is completely avoided. The technique is presented in the paper and it does not require a complicated computation.

\section{Description of presented ANN-based VPWM}

The space-vector modulation is basically a classification problem. Therefore, it is possible to use competitive type artificial neural network. The entire structure is shown in Fig. 1. For this purpose it is necessary to modify conventional competitive type ANN. Similarly that is a feedforward two-layer ANN and the inputs are stator reference voltages $u_{S \alpha}{ }^{*}, u_{S \beta}{ }^{*}$. This is followed by a layer of six neurons (the outputs $-n_{1}, n_{2}, \ldots, n_{6}$ ). These outputs correspond to the real part of the product of the reference voltage space vector $\underline{u}_{1}^{*}$ and one of the normalized nonzero switching vectors $\underline{u}_{k}$ $(k=1,2, \ldots, 6$; modulus is equal to 1$)$.

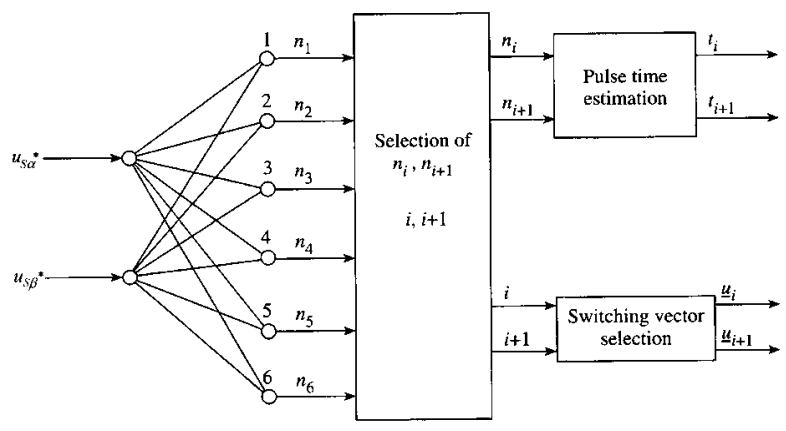

Fig. 1 ANN-based VPWM method

\footnotetext{
* Ing. Martin Kuchař, Prof. Ing. Pavel Brandštetter, CSc.

Department of Power Electronics and Electrical Drives, Faculty of Electrical Engineering and Computer Science, VŠB - Technical University of Ostrava, 17. Listopadu, 70833 Ostrava - Poruba, Czech Republic, Tel. +420-59-6994283, E-mail: martin.kuchar@vsb.cz
} 
Main equations leading to the final relation of the algorithm will be described here.

The non-zero switching vectors can be expressed as follows:

$$
\underline{u}_{\underline{k}}=\exp [j(k-1) \pi / 3]
$$

Real parts of the products of the reference voltage space vector and one of the normalized nonzero switching vectors are as follows:

$$
\begin{aligned}
n_{k} & =\operatorname{Re}\left(u_{k} u_{S}^{*}\right)=\operatorname{Re}\left[\exp [j(k-1) \pi / 3]\left(u_{S \alpha}{ }^{*}+j u_{S \beta}{ }^{*}\right)\right]= \\
& =\cos [(k-1) \pi / 3] u_{S \alpha}{ }^{*}-\cos [(2 k+1) \pi / 6] u_{S \beta}{ }^{*} \\
\mathrm{k} & =1,2, \ldots, 6
\end{aligned}
$$

From the relation (2) it is easy to express the weight matrix for competitive type ANN. Each neurons of ANN realises the inner product of the reference voltage vector and corresponding nonzero-switching vector.

$$
\mathrm{W}=\left[\begin{array}{rr}
1 & 0 \\
0.5 & \sqrt{3} / 2 \\
-0.5 & \sqrt{3} / 2 \\
-1 & 0 \\
-0.5 & -\sqrt{3} / 2 \\
0.5 & -\sqrt{3} / 2
\end{array}\right]
$$

It is clear that the presented weight matrix allows simple implementation of the ANN onto the microprocessor control system.

The pulse times can be evaluated from the largest network values in the following way.

Conventional VPWM utilizes the trigonometric function for determining right pulse times:

$$
\begin{aligned}
& t_{i}=m T_{s} \sin (60-\vartheta) \\
& t_{i}+1=m T_{s} \sin \vartheta \\
& t_{0}=T_{s}-t_{i}-t_{i}+1
\end{aligned}
$$

where $\vartheta$ is the angle between the reference stator voltage vector and the closest clockwise switching vector, $m$ is the modulation index and $T_{s}$ is the sampling period.

For the final equations of the pulse times it is necessary to use the following relations:

$$
\begin{aligned}
& n_{i}=I \underline{u}_{\underline{s}}^{*} I \cos \vartheta \\
& n_{i+1}=I \underline{u}_{\underline{s}}^{*} I \cos (60-\vartheta)
\end{aligned}
$$

then, by considering the trigonometric relationships

$$
\begin{aligned}
& \cos \vartheta=\left[\frac{2}{\sqrt{3}}\right]\left[\sin \frac{(60-\vartheta)}{2}+\sin \vartheta\right] \\
& \cos (60-\vartheta)=\left[\frac{2}{\sqrt{3}}\right]\left[\sin (60-\vartheta)+\sin \frac{\vartheta}{2}\right]
\end{aligned}
$$

and also equations $(6),(7),(8),(9)$, it possible to obtain the following pulse times equations from the relations (3), (4):

$$
\begin{aligned}
& t_{i}=\left(2 T_{s} / 3\right)\left(2 n_{i}-n_{i+1}\right) \\
& t_{i+1}=\left(2 T_{s} / 3\right)\left(2 n_{i+1}-n_{i}\right)
\end{aligned}
$$

The pulse time for zero switching vector can be obtained in the same way as in the conventional method:

$$
t_{0}=T_{s}-t_{i}-t_{i+1}
$$

It can be seen that the pulse times are estimated simply from the largest net values.

To summarise the important steps of the mentioned ANNbased VPWM:

1. Competitive type ANN evaluates the inner product of vectors $\underline{u}_{s}^{*}$ and $\underline{u}_{\underline{k}},(k=1,2, \ldots, 6)$.

2. Determination of the two largest values $n_{i}, n_{i+1}$ and corresponding indexes $i, i+1$.

3. The pulse times for adjacent switching space vectors are obtained by simple equations using $n_{i}, n_{i+1}$.

4. The switching combinations $\underline{u}_{i}, \underline{u}_{i+1}$ are selected according to the values $i$ and $i+1$.

\section{Simulation}

The induction motor drive was simulated in the program MATLAB-Simulink. The simulation stage was important to verify rightness of the presented algorithm and to find out behaviour of the drive. The simulation results have confirmed our assumptions, then the algorithm has been implemented into DSP. Stator voltage and current of the induction motor working in steady state are shown in Fig. 2.

\section{Induction motor drive implementation}

The mentioned algorithm was implemented into a digital signal processor TMS320C40. The processor works with 32-bit data in floating-point arithmetic. To test the method a wound-rotor induction machine $2,7 \mathrm{~kW}$ supplied by a frequency converter was used. The entire control system is shown in Fig. 3., and it was realized at the Technical University of Ostrava (Czech Republic).

The core of the system is the mentioned DSP, which utilizes additional information from other peripherals - Analog to Digital and Digital to analog converter (A/D, D/A), Block of Switching Pulses (BSP), Block of Evaluation of Rotor Position (BEPR) pro- 

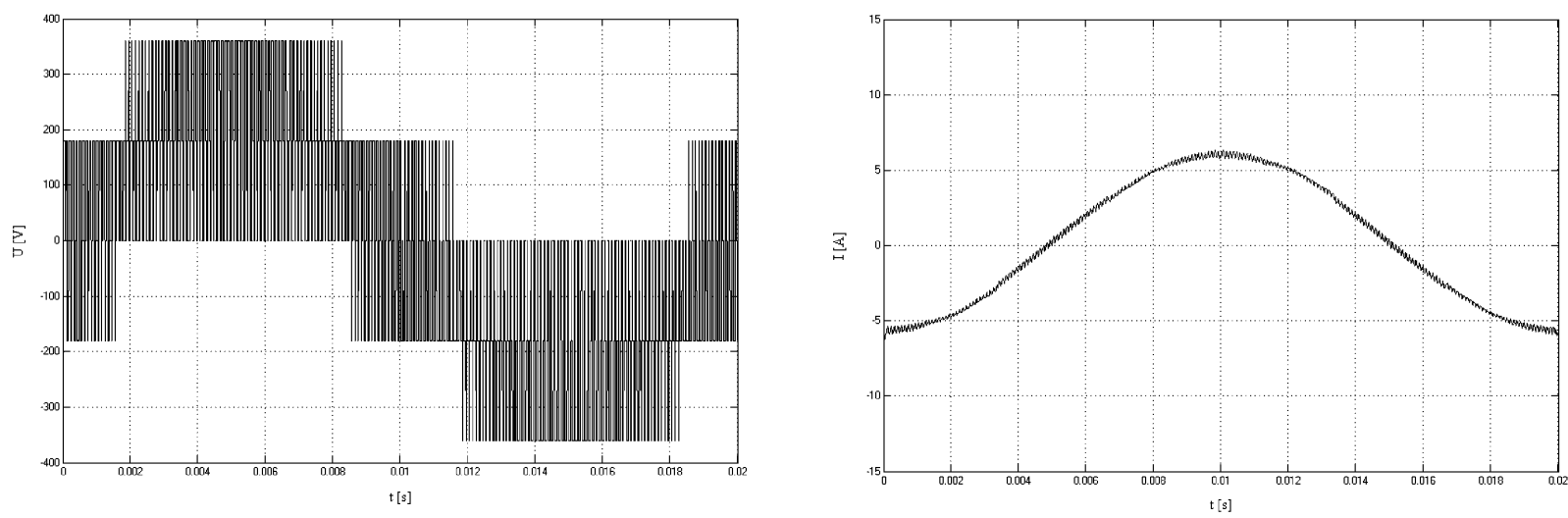

Fig. 2. Stator voltage and corresponding stator current while the motor is working in steady state $\left(f_{s}=10 \mathrm{kHz}, f_{\text {Uout }}=50 \mathrm{~Hz}(\right.$ MATLAB simulation $\left.)\right)$

cessing the signals from the incremental encoder. BSP is needful for right communication with a modern IGBT frequency converter (TFC). A Block of Isolated Amplifiers (BIA) is important to get signals of stator currents, which are monitored by means of LEM current sensors.

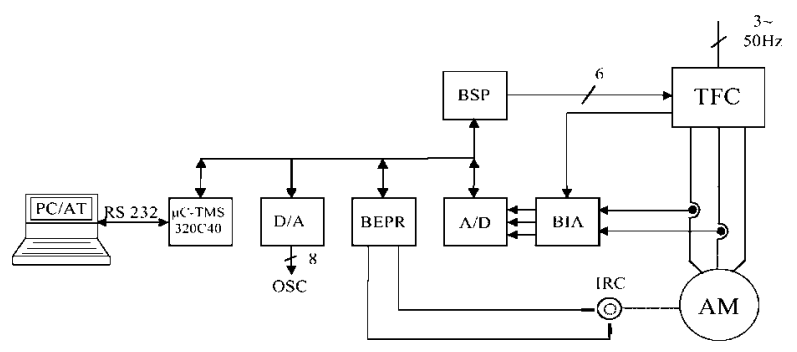

Fig. 3. DSP control system

\section{Experimental results}

In the chapter measured stator voltage and ANN-based vector pulse width modulator controls current of the motor will be pre- sented. You can then set the desired magnitude of output voltage and the desired output voltage frequency. The presented results were obtained by $\mathrm{U} / \mathrm{f}=$ const control. The switching strategy optimisation was implemented in the algorithm. The method is based on choosing the right switching vectors in the corresponding instants. After the zero switching vector the algorithm chooses one of two selected non-zero switching vectors by the following condition: the mentioned right vector has to cause minimum changes of IGBT switches in the frequency converter. This algorithm allows reduction of switches changes per one vector from 1.33 to 1 . It is clear that it reduces the switching losses of the converter. This application was used as the function block in vector control of an induction motor.

\section{Conclusions}

Conventional vector pulse-width modulation requires on-line computations with trigonometric functions. It causes the disadvantages mentioned at the beginning of the paper. It is possible to avoid the problems by means of the presented algorithm. The method utilizes a competitive artificial neural network and it works with
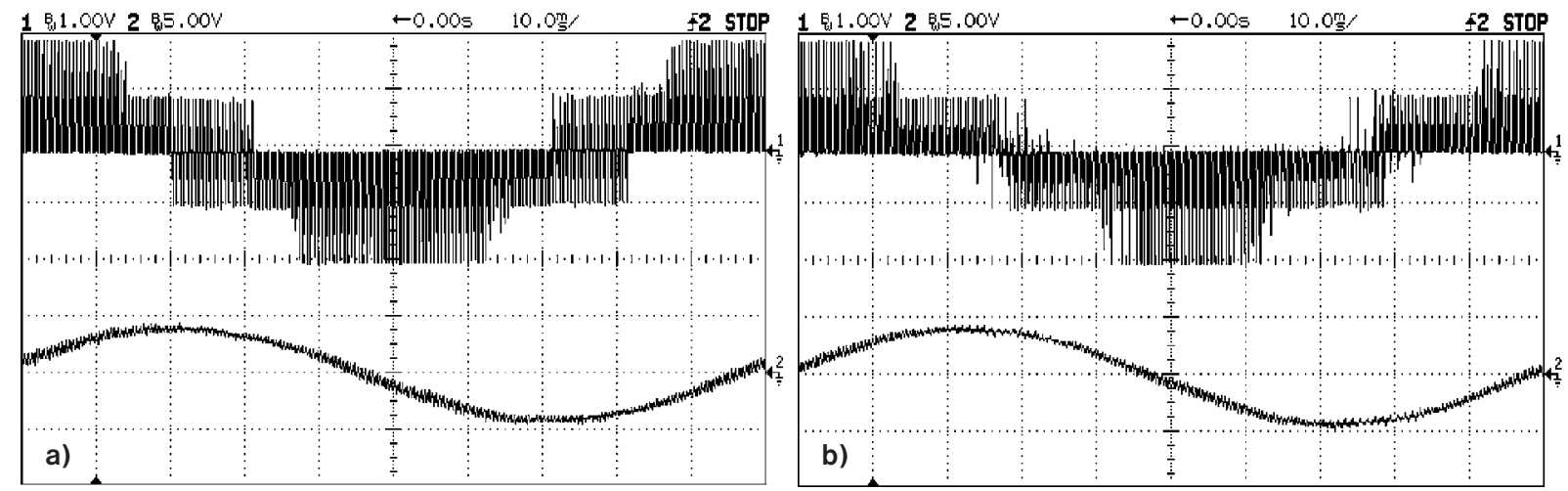

Figure 4. Stator voltage and corresponding stator current while the motor is working in steady state, ch1: $u_{s}=f(t), c h 2: i_{s}=f(t), V_{\text {DClink }}=300 \mathrm{~V}, f_{s}=2 \mathrm{kHz}, f_{\text {Uout }}=10 \mathrm{~Hz}, m_{u}=100 \mathrm{~V} / \mathrm{V}, m_{i}=1,5 \mathrm{~A} / \mathrm{V}$ a) not optimised switching strategy, b) optimised switching strategy 

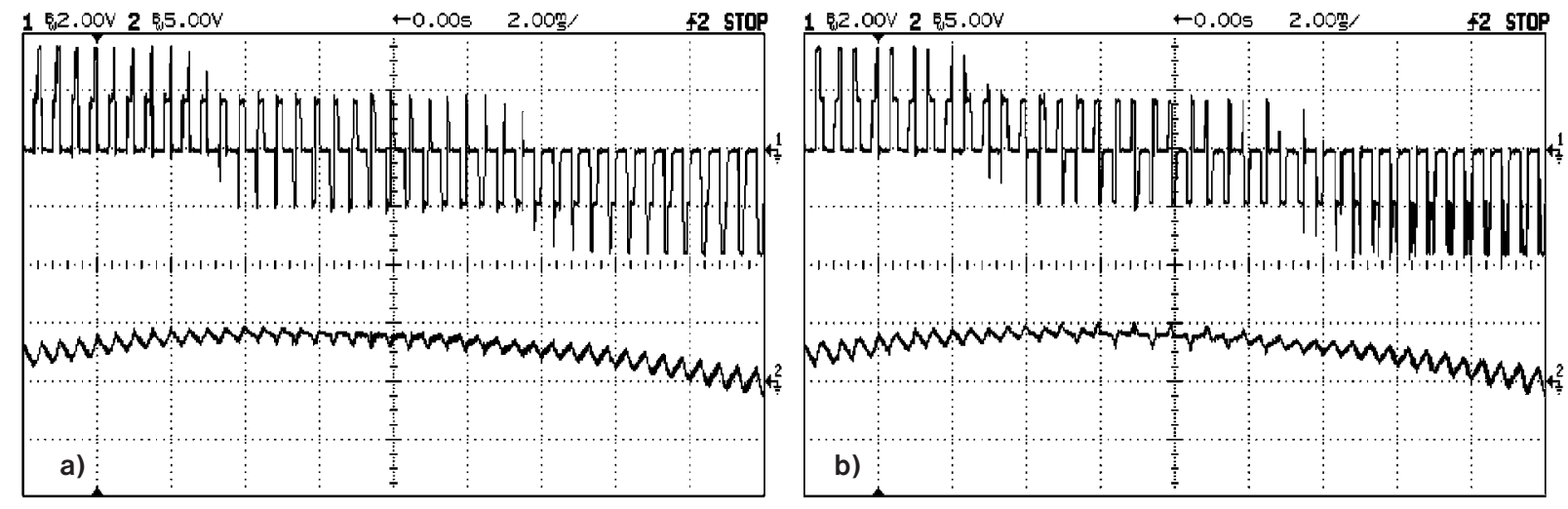

Figure 5. Stator voltage and corresponding stator current while the motor is working in steady state, ch1: $u_{s}=f(t), \operatorname{ch} 2: i_{s}=f(t), V_{\text {DClink }}=540 \mathrm{~V}, f_{s}=2 \mathrm{kHz}, f_{\text {Uout }}=20 \mathrm{~Hz}, m_{u}=100 \mathrm{~V} / \mathrm{V}, m_{i}=1,5 \mathrm{~A} / \mathrm{V}$

a) not optimised switching strategy, b) optimised switching strategy

simple mathematical operations. It is clear that this type of VPWM is very simple to be implemented into microprocessor systems. Rightness of the algorithm has been verified by the simulations, then the method including the switching strategy optimisation was implemented into DSP powered by Texas Instruments. The mentioned strategy reduces switching losses of the converter. In the end, VPWM was integrated into vector control of an induction motor and all experimental results were presented at the EPE 2003 conference.

\section{Acknowledgement}

In the paper there are results of the project LN00B029, which was supported by The Ministry of Education of the Czech Republic.

\section{References}

[1] VAS, P.: Artificial-Intelligence-Based Electrical Machines and Drives, Oxford Science Publication, 1999, ISBN 019859397 X

[2] BRANDSTETTER, P.: AC regulation drives - Modern control methods, VSB-TU Ostrava 1999, ISBN 80-7078-668-X

[3] NEBORAK, I.: Modelling and simulation of electrical regulation drives, VSB-TU Ostrava 2002, ISBN 80-248-0083-7

[4] TEXAS INSTRUMENTS: TMS 320C40 Users Guide, Digital Signal Processing Product, 1995

[5] BRANDSTETTER, P., KUCHAR, M., PALACKY, P., VINKLAREK, D.: Sensorless Induction Motor Drive with Vector Control, EPEPEMC 2002, Dubrovnik 2002

[6] DEMUTH, H., BEALE, M.: Neural Network Toolbox, for use with Matlab, ver. 4.

[7] FEDOR, P., PERDUKOVA, D., TIMKO, J.: Study of Controlled Structure Properties with Reference Model, Acta Technica, ISSN 00017043, CSAV 46, 2001. 